\title{
Optimization of Machining Parameters for the Turning Process of AISI 316 L Stainless Steel and Taguchi Design
}

\author{
G. BASMACI*
}

Mehmet Akif Ersoy University, Faculty of Engineering and Architecture, 15100 Burdur, Turkey

In this study the effect of feed rate, depth of cut and cooling system on surface roughness and cutting force during machine turning of AISI 316L stainless steel is investigated. The Taguchi method was used for optimization of machine turning. Furthermore, variance analysis was performed to determine the effect of each parameter on the results. As a result of this analysis, the effect of feed rate, depth of cut and cooling system on surface roughness and cutting force during machine turning of AISI 316L stainless steel was determined. Consequently, the ANOVA method was used to determine optimal parameter levels.

DOI: 10.12693/APhysPolA.134.260

PACS/topics: optimization, AISI 316 L, Taguchi design, turning, ANOVA

\section{Introduction}

The steel materials used in the manufacturing industry is becoming more advanced day by day. Stainless steel is commonly used in a wide range of applications in the manufacturing sector with its high mechanical properties, corrosion resistance, and low thermal conductivity [1]. Although they are more expensive compared to other forms of steel, stainless steel is becoming increasingly popular for use in many fields ranging from food to health, chemistry to electronics, from defense industry to nuclear power plants and automotive to aerospace, due to their high mechanical properties and unique corrosion resistance [2-4]. Stainless steel is a type of steel which contains 11-18\% chromium in its composition [5].

Austenitic and ferritic stainless steel is used particularly in machinery and manufacturing industry. These forms of steel fall under the difficult to machine materials class with their low thermal conductivity properties. Low thermal conductivity leads to high shear force, high cutting temperatures, rapid tool wear, produces difficult to break chips, causes chips to bond to the cutting edge, and leads to poor surface quality [6]. Also, the energy used for plastic deformation of the workpiece during machine turning is converted to heat and it is well known that heat mostly occurs in the primary deformation zone. However, heat generated during deformation is closely associated with friction and shear force in the tool-chip interface which vary according to tool geometry and cutting parameters. Tool-chip contact length and therefore tool geometry directly affects tool life and machining efficiency [7]. In recent years, it is possible to come across many experimental studies investigating the effects of cutting parameters on shear force and surface

*e-mail: gbasmaci@mehmetakif.edu.tr roughness occurring during machining of various forms of stainless steel. In one of these studies, the machinability of AISI 304 and AISI 316 stainless steel with coated cemented carbide cutting tools was investigated and cutting speed was reported as an important parameter for surface roughness $\left(R_{a}\right)$ [8].

In another study, the $F_{c}$ generated during the turning of AISI 304 austenitic stainless steel with titanium carbide coated cutting tool, was theoretically and experimentally evaluated and it was indicated that the theoretical approach could be used with $80 \%$ average accuracy [9]. $\quad R_{a}$ is reported to decrease parallel to the decrease in cutting sound pressure level during the turning of AISI 304 stainless steel at low feed rate and high cutting speeds [10]. In another study, the verification tests conducted according to the optimum cutting parameters for surface roughness and cutting force during turning of austenitic stainless steel resulted in a $23.4 \%$ improvement [11]. A variance analysis on the $R_{a}$ resulting from the machining of AISI 304 stainless steel, revealed that feed rate had a $51.84 \%$ effect on $R_{a}[12]$.

Time, volume, and efficiency of production are not the only factors that should be taken into consideration in the assessment of success of a production method. Other important considerations must include the effect on the environment and human health. Machine turning applications which use cooling techniques that respect human health and the environment have been developed. The performance characteristics of the alternative cooling technique were found to be superior to the conventional cooling techniques [13-20]. The minimum quantity librication (MQL) technique which delivers reduced tool wear and improved surface quality thanks to a reduction in the heat generated in the tool-chip and workpiece-chip significant cutting zone are important results [21]. Also liquid nitrogen, and carbon dioxide is also used as an alternative cooling system for the cooling of the cutting zone. A $55 \%$ reduction in edge wear was reported following the use of liquid nitrogen cooling [22]. 
In this study the effect of feed rate, depth of cut and cooling system on surface roughness and cutting force during machine turning of AISI 316L stainless steel is investigated. The Taguchi technique was used in the optimization of the turning process. Furthermore, variance analysis was conducted to determine the effect of each parameter on the results. As a result of this analysis, the effect of feed rate, depth of cut and cooling system on surface roughness and cutting force during machine turning of AISI 316L stainless steel was determined.

\section{Materials and method}

AISI 316L was used as material for the purposes of this study. The experiment samples were rod shaped $130 \mathrm{~mm}$ in length and $25 \mathrm{~mm}$ in diameter. During the machining process, CNMG $120408 \mathrm{~mm}$ cutting tips produced by Sandvik company were used. The Johnford TC 35 CNC Fanuc OT, an $x-z$ axis CNC machine was used during the experiment. A perhometer M1 type surface roughness meter manufactured by Mahr was used in the experiment. Surface roughness can be determined with various parameters according to DIN, ISO, JIN, AISI standards. Once the obtained value is displayed on the screen, it can be printed out in any surface roughness parameter such as $R_{a}, R_{z}$, etc. A KISTLER 9121 dynamometer with KISTLER 5019b type load amplifier and the DynoWare analysis soft-ware was used for power measurement during the experiments.

3 levels were set between 0.1 and $0.3 \mathrm{~mm} / \mathrm{rev}$ for the feed rate parameter, and 0.5 and $1.5 \mathrm{~mm}$ for depth of cut. Dry, MQL, and $\mathrm{CO}_{2}$ options were examined for the cooling system factor. Table I shows cutting parameters.

Cutting parameters

TABLE I

\begin{tabular}{c|c|c|c}
\hline \hline Factors & Level 1 & Level 2 & Level 3 \\
\hline feed rate $[\mathrm{mm} / \mathrm{rev}]$ & 0.1 & 0.2 & 0.3 \\
\hline depth of cut $[\mathrm{mm}]$ & 0.5 & 1 & 1.5 \\
\hline cooling system & dry & MQL & $\mathrm{CO}_{2}$
\end{tabular}

\subsection{Taguchi design}

The Taguchi parametric design is a very effective design tool offering simple and systematic qualitative optimal design at a relatively low cost. Taguchi proposed a statistical measure of performance called signal to noise ratio $(\mathrm{S} / \mathrm{N}$ ratio), in order to obtain the optimum process parameters setting. This ratio considers both the mean and the variability. In addition to the $\mathrm{S} / \mathrm{N}$ ratio, ANOVA is used as an indicator of the influence of process parameters on performance measures. Three categories of performance characteristics, were proposed by Taguchi in the analysis of the $\mathrm{S} / \mathrm{N}$ ratio, which are, the smaller the better, the higher the better, and the nominal the better [23]. The experiments performed according to Taguchi L9 orthogonal array, levels of the set of parameters are given in Table II.
TABLE II

The orthogonal array $L_{9}\left(3^{2}\right)$ based on the Taguchi method

\begin{tabular}{c|c|c|c}
\hline \hline \multirow{2}{*}{ Exp. no. } & \multicolumn{3}{|c}{ Control factor levels } \\
\cline { 2 - 4 } & $\begin{array}{c}\text { Feed } \\
\text { rate }[\mathrm{mm} / \mathrm{rev}]\end{array}$ & $\begin{array}{c}\text { Depth } \\
\text { of cut }[\mathrm{mm}]\end{array}$ & $\begin{array}{c}\text { Cooling } \\
\text { system }\end{array}$ \\
\hline 1 & 0,1 & 0,5 & dry \\
\hline 2 & 0,1 & 1 & $\mathrm{MQL}$ \\
\hline 3 & 0,1 & 1,5 & $\mathrm{CO}_{2}$ \\
\hline 4 & 0,2 & 0,5 & $\mathrm{MQL}$ \\
\hline 5 & 0,2 & 1 & $\mathrm{CO}_{2}$ \\
\hline 6 & 0,2 & 1,5 & dry \\
\hline 7 & 0,3 & 0,5 & $\mathrm{CO} 2$ \\
\hline 8 & 0,3 & 1 & dry \\
\hline 9 & 0,3 & 1,5 & $\mathrm{MQL}$
\end{tabular}

\section{Analysis and discussion}

In order to specify both reactive and non-reactive ions ANOVA effects of experimental reactor parameters can be used. Tables III and IV indicate to the ANOVA conducted for $R_{a}$ and cutting force, respectively. Whether a parameter to find out the reaction of an interaction that has an effect in the ANOVA analysis a $P$ (importance / probability) value is checked. If $95 \%$ reliability interval is considered, then a $P$ value of $P<0.05$ (5\% importance by value) indicates that the parameter is effective. Contribution of every factor on the total [24-28].

\subsection{Analysis of variance (ANOVA)}

Variance analysis, a decision tool based on statistics, was performed to demonstrate the differences between the factors affecting the performance of machining process. Variance analysis (the analysis of variance, ANOVA) is used in order to determine the impact of the different values of independent variable(s) on the dependent variable.

Table III shows the results of the ANOVA analysis performed for $R_{a}$. When the results are evaluated, the feed rate parameter stands out as the most influential factor for the confidence interval of $95 \%$ with a $P$-value below 0.05 (Table III).

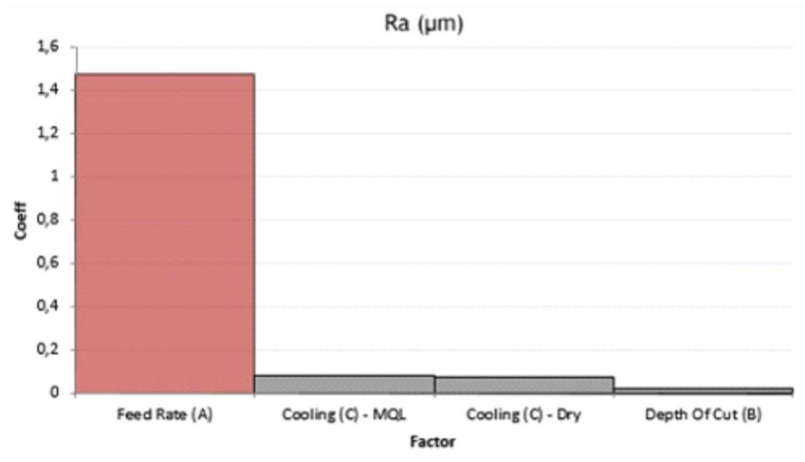

Fig. 1. Pareto chart for parameters affecting surface. 
ANOVA analysis results for $R_{a}$

TABLE III

\begin{tabular}{|c|c|c|c|c|c|c|c|c|c|}
\hline \multicolumn{2}{|c|}{ Factor } & Coeff & $\mathrm{SE}$ & $\mathrm{T}$ & Seq SS & Adj SS & Adj MS & $\mathrm{F}$ & $\mathrm{P}$ \\
\hline \multicolumn{2}{|l|}{ const } & 1.8508 & 0.1341 & 13.804 & & & & & 0.000 \\
\hline \multicolumn{2}{|c|}{ feed rate $(\mathrm{A})$} & 1.4777 & 0.1642 & 8.9985 & 13.101 & 13.101 & 13.101 & 80.974 & 0.001 \\
\hline \multirow{2}{*}{\multicolumn{2}{|c|}{$\begin{array}{l}\text { depth of cut }(\mathrm{B}) \\
\text { cooling }(\mathrm{C})\left(\mathrm{ref}=\mathrm{CO}_{2}\right)\end{array}$}} & -0.0207 & 0.1642 & -0.1259 & 0.0026 & 0.0026 & 0.0026 & 0.0158 & 0.906 \\
\hline & & & & & 0.0354 & 0.0354 & 0.0177 & 0.1094 & \\
\hline \multicolumn{2}{|c|}{ dry } & 0.0696 & 0.1896 & 0.3668 & & & & & 0.732 \\
\hline \multicolumn{2}{|l|}{ MQL } & -0.0824 & 0.1896 & -0.4348 & & & & & 0.686 \\
\hline total & 13.786 & & & regression & 13.139 & 13.139 & 3.2847 & & \\
\hline$R^{2}$ & 0.9531 & $\operatorname{Adj} R^{2}$ & 0.9061 & std error & 0.4022 & $F$ & 20.302 & $\operatorname{Sig} F$ & 0.0064 \\
\hline
\end{tabular}

ANOVA analysis results for cutting forces

TABLE III

\begin{tabular}{|c|c|c|c|c|c|c|c|c|c|}
\hline \multicolumn{2}{|c|}{ Factor } & Coeff & $\mathrm{SE}$ & $\mathrm{T}$ & Seq SS & Adj SS & Adj MS & $\mathrm{F}$ & $\mathrm{P}$ \\
\hline \multicolumn{2}{|l|}{ const } & 416.155 & 45.885 & 9.0694 & 282423 & & & & 0.001 \\
\hline \multicolumn{2}{|c|}{ feed rate $(\mathrm{A})$} & 129.379 & 56.198 & 2.3022 & 100434 & 100434 & 100434 & 5.3001 & 0.083 \\
\hline \multicolumn{2}{|c|}{ depth of cut (B) } & 169.929 & 56.198 & 3.0238 & 173255 & 173255 & 173255 & 9.1431 & 0.039 \\
\hline \multicolumn{2}{|c|}{ cooling $(\mathrm{C})\left(\right.$ ref $\left.=\mathrm{CO}_{2}\right)$} & & & & 8735.27 & 8735.27 & 4367.64 & 0.2305 & \\
\hline \multicolumn{2}{|c|}{ dry } & -12.459 & 64.892 & -0.192 & & & & & 0.857 \\
\hline \multicolumn{2}{|l|}{ MQL } & -30.369 & 64.892 & -0.468 & & & & & 0.664 \\
\hline \multirow{2}{*}{ total } & \multirow{2}{*}{358220} & & & regression & 282423 & 282423 & 70605.8 & & \\
\hline & & & & error & 75797.0 & 75797.0 & 18949.3 & & \\
\hline$R^{2}$ & 0.7884 & $\operatorname{Adj} R^{2}$ & 0.5768 & std error & 137.656 & $F$ & 3.726 & $\operatorname{Sig} F$ & 0.1154 \\
\hline
\end{tabular}

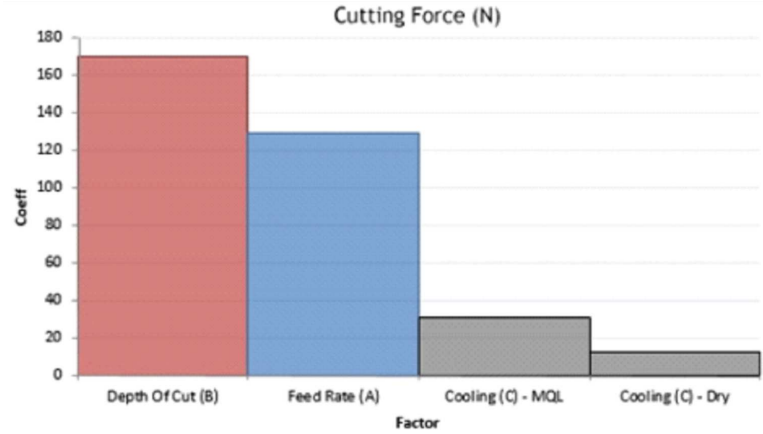

Fig. 2. Pareto chart for parameters affecting cutting forces.

As the significance value for the feed rate parameter is found to be below $5 \%$ when the factors affecting surface roughness is analysed with ANOVA, it was determined as the most effective parameter. Cooling and depth of cut parameters on the other hand does not show any statistically significant difference.

Parameters that affect surface roughness and effect rates are shown in the Pareto chart presented in Fig. 1 as feed rate, cooling MQL and dry cooling and depth of cut, respectively. According to the regression equation $R^{2}$ value is calculated as 0.9531 and $F$ value was found as 20.302 .

As the depth of cut parameter is found to be below 0.05, in the ANOVA analysis for parameters affecting cutting force, it was determined as the factor affecting

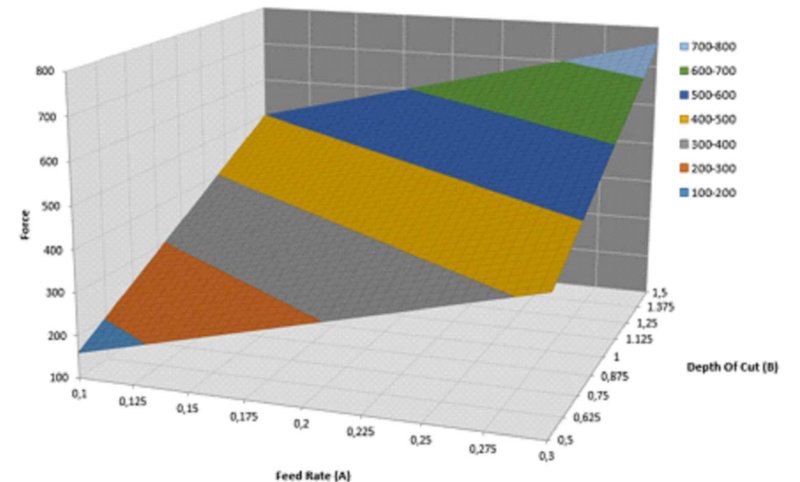

Fig. 3. Interactive surface graphic for feed rate and dept of cut as parameters affecting the cutting force.

cutting force the most. Despite being above the significance value of 0.05 , the feed rate parameter was found to be quite close to the threshold value. No significant difference was determined between the dry and MQL values for the cooling parameter. The results of ANOVA analysis for cutting forces are given in Table IV.

Parameters that affect cutting forces and effect rates are shown in the Pareto chart below as depth of cut, feed rate, MQL cooling and dry cooling, respectively. According to the regression equation $R^{2}$ value is calculated as 0.7884 , and $F$ value was found as 3.726 .

Figure 2 shows the effect levels of the feed rate, depth of cut, cooling parameters affecting cutting forces in the form of a Pareto chart. 


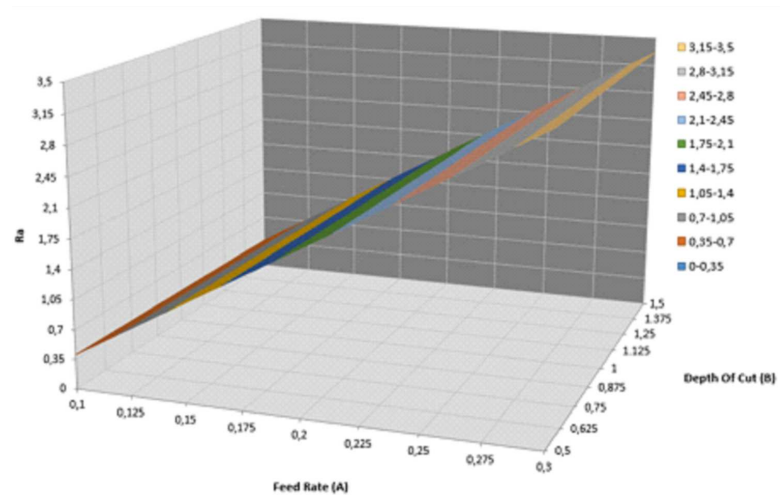

Fig. 4. Interactive surface graphic for feed rate and depth of cut as parameters affecting surface roughness.

An interactive graph of depth of cut and feed rate as factors affecting cutting forces is given in Fig. 3. According to this graph, it is clearly seen that when both feed rate and depth of cut values decrease, cutting forces also decrease and when both values increase cutting forces also increase.

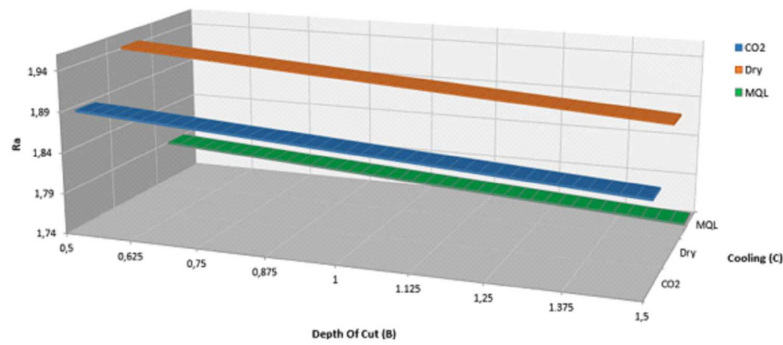

Fig. 5. Interactive surface graphic for depth of cut and cooling as parameters affecting surface roughness.

The depth of cut and feed rate parameters which affect surface roughness the most are shown in the figure below (Fig. 4). According to this, although no significant differences were found in terms of surface roughness when depth of cut is changed within the predetermined range, it is observed that surface roughness increases in direct proportion when the value of the feed rate parameter is increased.
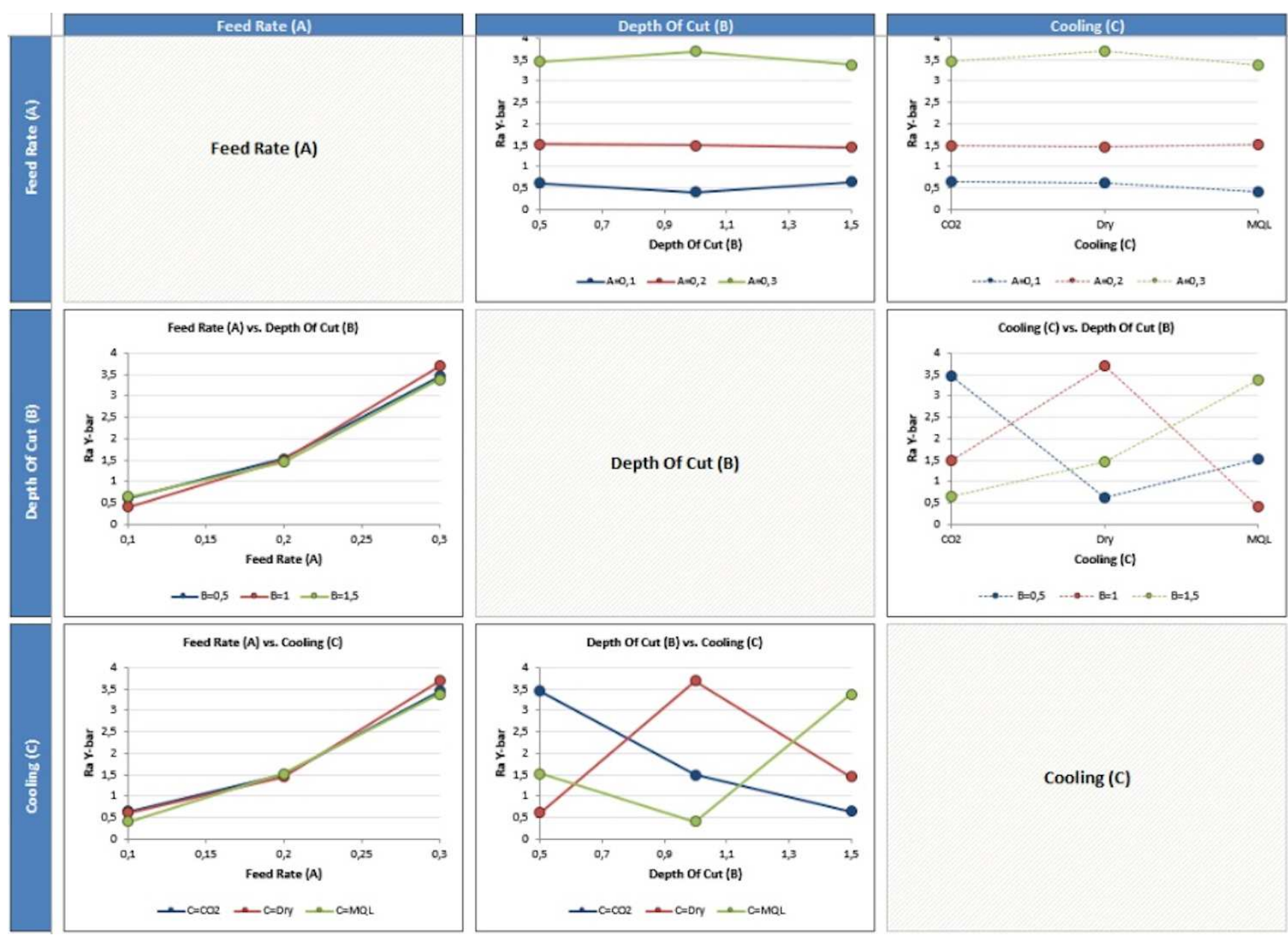

Fig. 6. Interactive surface graph for feed rate, depth of cut and cooling as parameters affecting surface roughness. 
When depth of cut and cooling parameters presented in Fig. 5 as parameters affecting surface roughness are evaluated separately, MQL appears as the most suitable method for minimizing surface roughness, followed by $\mathrm{CO}_{2}$ and dry methods.

The interaction between each of the three different levels for feed rate, depth of cut and cooling parameters are shown in Fig. 6. According to this, there was no significant interaction between depth of cut and feed rate and it can also be said that no significant interaction exists between cooling and feed rate. However, it is clearly seen from the graph that there is an obvious interaction between cooling and depth of cut parameters. While dry machining increases $R_{a}$ level, the use of MQL gives the best results for surface roughness. When depth of cut takes the lowest value, surface roughness is also at the lowest level and when feed rate is increased, surface roughness also increases.

\section{Conclusion}

In this study, cutting force and surface roughness values are measured during the CNC machining of $316 \mathrm{~L}$ stainless steel (widely used in the defense industry, etc.) and basic parameters affecting these values and their effect levels are determined using statistical methods.

First, the number of measurements to be performed and parameter values for measuring surface roughness with the Taguchi method, were determined. Then the obtained values were analyzed using ANOVA and the relational degree between parameters were determined.

Cutting forces must be minimized, in order to increase the life span of the cutting tool. As a result of these measurements and calculations, depth of cut and feed rate were determined as factors that affect cutting forces the most, as can be seen in the Pareto chart presented in Fig. 3. The lowest values for cutting force were obtained in experiment No. 1.

\section{References}

[1] T. Kosa, P. Ronald, in: Handbook: Machining, Vol. 16, 9th ed., Ed. J.R. Davis, American Society for Metals, Metals Park (OH) 1989, p. 59.

[2] R. M'Saoubi, J.C. Outeiro, B. Changeux, J.L. Lebrun, A.M. Dias, J. Mater. Process. Technol. 96, 225 (1999).

[3] J.D. Darwin, D.M. Lal, G. Nagarajan, J. Mater. Process. Technol. 195, 241 (2008).
[4] J.C. Outeiro, D. Umbrello, R. M'Saoubi, Int. J. Machine Tools Manufacture 46, 1786 (2006).

[5] B.K. Agrawal, Introduction to Engineering Materials, Mc Graw-Hill, New Delhi 1983.

[6] C. Maranhao, J.P. Davim, Simulat. Modell. Pract. Theory 18, 139 (2010).

[7] I. Korkut, M. Boy, I. Karacan, U. Seker, Mater. Des. 28, 2329 (2007).

[8] İ. Ciftci, Tribol. Int. 39, 565 (2006).

[9] Ö. Tekaslan, N. Gerger, M. Günay, U. Şeker, Pamukkale Üniversitesi Mühendislik Bilimleri Dergisi 13, 129 (2007), (in Turkish).

[10] Z. Tekiner, S. Yeşilyurt, Mater. Des. 25, 507 (2004).

[11] S. Li, Y. Liu, R. Zhu, H. Li, W. Ding, Appl. Mech. Mater. 34-35, 1829 (2010).

[12] D.P. Selvaraj, P. Chandramohan, J. Eng. Sci. Technol. 5, 293 (2010).

[13] A.E. Diniz, J.R. Ferreira, F.T. Filho, Int. J. Machine Tools Manufact. 43, 317 (2003).

[14] H.A. Kishawy, M. Dumitrescu, M.A. Elbestawi, Int. J. Machine Tools Manufact. 45, 219 (2005).

[15] N.R. Dhar, M. Kamruzzaman, M. Ahmed, J. Mater. Process. Technol. 172, 299 (2006).

[16] F. Itoigawa, T.H.C. Childs, T. Nakamura, W. Belluco, Wear 260, 339 (2006).

[17] N.R. Dhar, M.W. Islam, S. Islam, M.A.H. Mithu, J. Mater. Process. Technol. 171, 93 (2007).

[18] E.O. Ezugwu, J. Bonney, R.B. Da Silva, O. Çakır, Int. J. Machine Tools Manufact. 47, 884 (2007).

[19] A. Attanasio, M. Gelfi, C. Giardini, C. Remino, Wear 260, 333 (2006).

[20] C. Bruni, A. Forcellese, F. Gabrielli, M. Simoncini, Int. J. Machine Tools Manufact. 46, 1547 (2006).

[21] J. Liu, R. Han, Y. Sun, Int. J. Machine Tools Manufact. 45, 687 (2005).

[22] M. Stanford, P.M. Lister, C. Morgan, K.A. Kibble, J. Mater. Process. Technol. 209, 961 (2009).

[23] P.J. Ross, Taguchi Techniques for Quality Engineering: Loss Function, Orthogonal Experiments, Parameter and Tolerance Design, 2nd Edition, McGrawHill, New York 1996.

[24] İ. Asiltürk, S. Neşeli, Measurement 45, 785 (2012).

[25] G. Basmacı, Ph.D. Thesis, Marmara University, Institute of Science and Technology, 2012.

[26] M. Ay, Acta Phys. Pol. A 131, 349 (2017).

[27] G. Basmaci, M. Ay, Acta Phys. Pol. A 131, 354 (2017).

[28] M. Ay, G. Basmacı, Online J. Sci. Technol. 6, No. 1 (2016). 